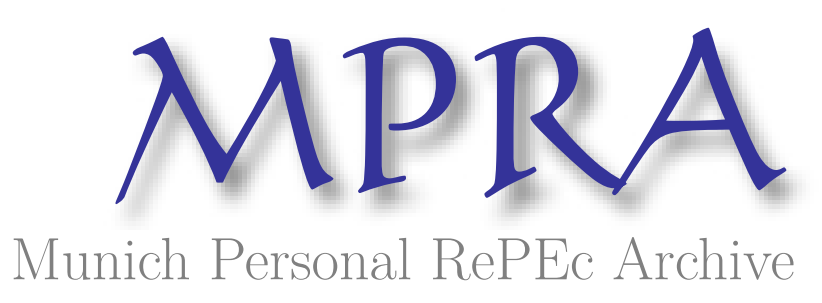

\title{
The Geographic Dynamics of Deposit Insurance
}

Defina, Ryan

International Association of Deposit Insurers

15 April 2021

Online at https://mpra.ub.uni-muenchen.de/110557/

MPRA Paper No. 110557, posted 23 Nov 2021 09:27 UTC 


\section{The Geographic Dynamics of Deposit Insurance}

\section{Executive summary}

Geography plays a fundamental role in today's interconnected world. Financial flows operate within a multitude of regulatory and supervisory parameters often heavily influenced by regional factors. While deposit insurance is one factor affecting these flows, it too has been influenced by regional factors, particularly in the past 20 years with the rapid growth and development of deposit insurance systems, and has undergone substantial changes as a result. Understanding geographic dynamics in deposit insurance design enables policy makers to better understand the impact of regional factors on the features of deposit insurance systems and vice versa. Correlation between deposit insurer features in neighbouring jurisdictions offers the potential to facilitate collaboration under the grounds of common history and institutional development, but also introduces many challenges to multiple and bilateral coordination. We explore these issues further and highlight considerations for deposit insurance research, training and more targeted technical assistance initiatives.

This paper investigates the associations between the features of deposit insurance systems and geography using a relatively simple statistical approach, and quantified through analysis of data collected by IADI. The results focus on a cross-sectional analysis of 2019 Annual Survey results ${ }^{1}$. An implicit assumption is made that relationships observed in 2019 data are broadly representative of the true underlying dynamics between variables of interest and geography, although further analysis incorporating a time dimension would provide clarity on this assumption.

Results suggest that geography is an important factor to consider when exploring a range of deposit insurance data items. However, this effect does not play a role for all aspects of deposit insurance systems, and is subject to a number of caveats. In some instances, the age of deposit insurers (a proxy for maturity in system design and implementation) can influence more than the region as a whole. Moreover, sample sizes used are relatively small so this needs to be taken into account when reviewing the results.

Future research directions in this area could seek to broaden the suite of data items considered; conduct a targeted follow-up to further unpack the economic, financial, legal and cultural dynamics driving both inter- and intra-regional variation; or explicitly consider temporal dynamics through appraising longitudinal panels of deposit insurance metrics.

\section{Introduction and purpose}

The paper seeks to explore the extent to which geography potentially influences the design of financial systems and their operations, with a focus on implications for deposit insurance. There is considerable ongoing discussion within the deposit insurance community regarding the relative weight that should be assigned to regional effects when calibrating training, technical assistance and research initiatives. This paper attempts to offer additional insights to this discussion.

In terms of the key variables examined, we start with the age of the deposit insurer (DI) hypothesised as an alternative factor driving heterogeneity globally. This variable is viewed as a reasonable proxy for the maturity of a financial system and thus provides a metric for exploring common development and evolution of Dls over time. For instance, institution age is shown to be highly correlated with system mandate. Older deposit insurance systems are on average, ceteris paribus, more likely to hold extended powers beyond the power to perform a payout of deposits. This provides some evidence to suggest that age is a fundamental driver of deposit insurer system development. As such, it is

\footnotetext{
${ }^{1}$ The associated reference period is December-end 2019.
} 
important to ensure that regional effect estimates are not simply driven by the relative composition and/or clustering of age within a given group of jurisdictions. Disentangling the relationship between region and age enables policymakers to adapt expectations and optimise policy parameters more effectively. The charts below demonstrate the interactions between region, age and mandate.

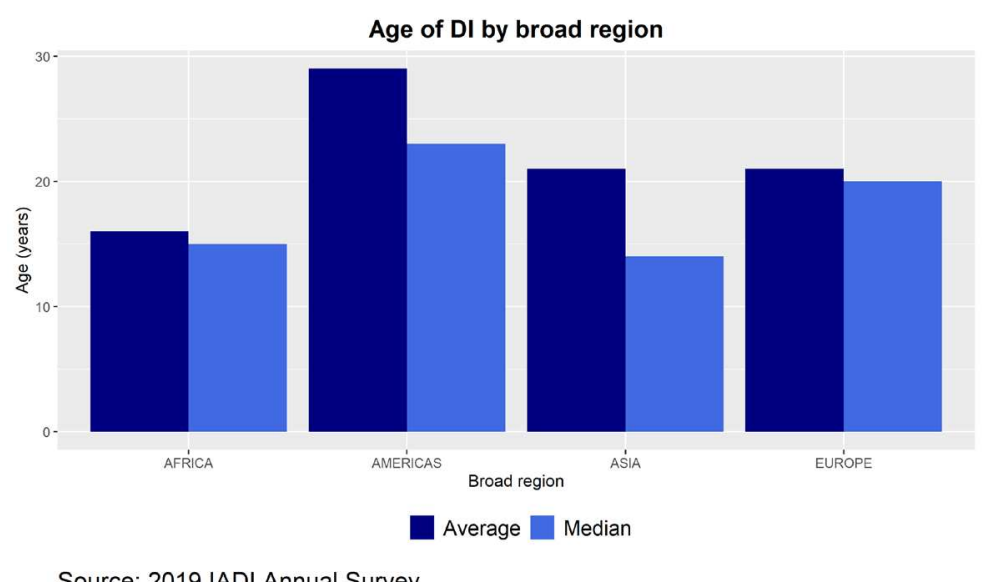

Source: 2019 IADI Annual Survey

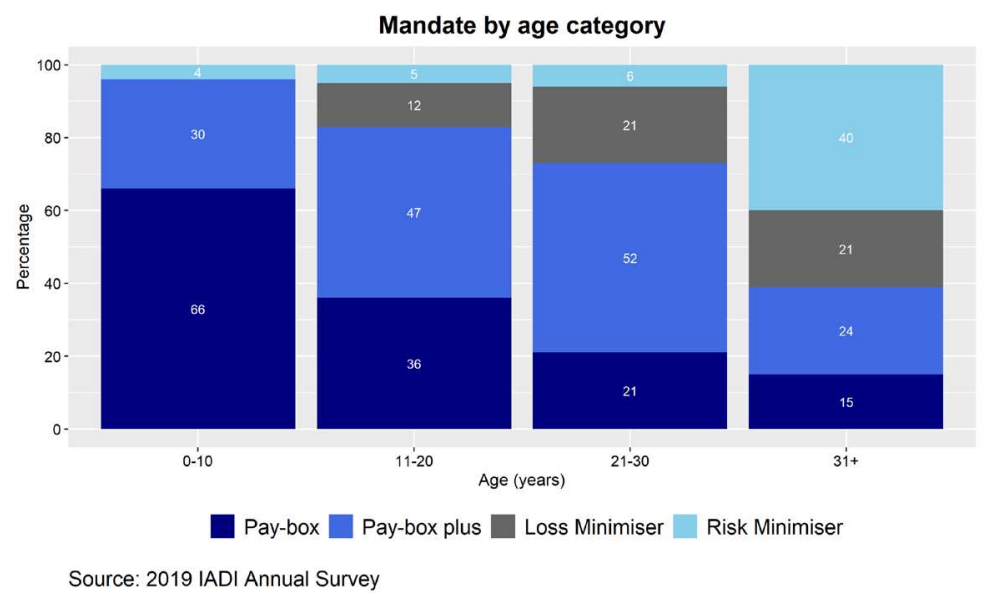

\section{Methodology and results}

\subsection{Data issues}

Six variables are focused on throughout the rest of this paper. These are chosen for a variety of reasons. First, they cover important design features of deposit insurance systems, to enable some degree of broad overlap to deposit insurance key metrics as a whole. We choose variables that are likely to be reported with a high degree of accuracy by survey respondents, removing the need to incorporate any complicated bias-correcting measurement error models. Response rates must be high, which mitigates potential non-response bias skewing results. Finally, different variable types are considered such as continuous, binary and counts to ensure conclusions can be broadly applied. 


\begin{tabular}{|c|c|c|c|c|}
\hline \multicolumn{5}{|c|}{ TABLE ONE: VARIABLES OF INTEREST } \\
\hline ACRONYM & TOPIC & $\begin{array}{l}\text { QUESTION } \\
\text { NUMBER }^{2}\end{array}$ & SURVEY CONCEPT & NOTES \\
\hline INDEP & Structure & Q8 & DI legal structure & $\begin{array}{l}\text { Independent = 1; } \\
\text { Not independent }=0\end{array}$ \\
\hline COVER & Coverage & Q36 & Coverage ratio $^{3}$ & $\begin{array}{l}\text { Total covered deposits / } \\
\text { Total eligible deposits }\end{array}$ \\
\hline PAYOUT & Payout & Q39 & $\begin{array}{l}\text { Targeted number of days to begin } \\
\text { deposit reimbursement? }\end{array}$ & Number of days \\
\hline FUND & Funding & Q50 & Actual fund size & $\begin{array}{l}\text { Fund size / } \\
\text { Total eligible deposits }\end{array}$ \\
\hline PAYBOX & Structure & Q9 & Is the DI a paybox? & $\begin{array}{l}\text { Paybox = } 1 ; \\
\text { Not paybox }=0^{4}\end{array}$ \\
\hline PRIVATE & Structure & Q2 & Is the DI privately administered? & $\begin{array}{l}\text { Private }=1 \\
\text { Public }=0\end{array}$ \\
\hline
\end{tabular}

The simplest analysis of region-level ${ }^{5}$ effects can be conducted through summary statistics, with a focus on the mean, based on data from the 2019 IADI Annual Survey. Formal tests to confirm observations after controlling for statistical variation will follow. Notably observations for each respective variable of interest include:

> Independence of the DI legal structure was marginally more prevalent in $\mathrm{ASIA}^{6}$, but with little overall geographic variation to speak of. A statistically significant region effect is highly unlikely based on these figures alone.

$>$ Coverage ratios are much higher in the AMERICAS and EUROPE compared to other regions ${ }^{7}$. Strong variation is observed, with a likely region effect apparent.

$>$ Days to payout is again highest in the AMERICAS, but also in AFRICA, and more than three times the lowest figure in EUROPE region. A region effect is expected here.

\footnotetext{
${ }^{2}$ Question numbers are as per the 2019 IADI Annual Survey questionnaire.

${ }^{3}$ Coverage ratio is typically defined in two ways - proportion of accounts/depositors covered as a share of all accounts/depositors or; total value of covered deposits as a share eligible deposits. This paper utilises the latter.

${ }^{4}$ Attempts were made to disaggregate further into paybox plus, loss minimiser and risk minimiser DI system mandates. However, these offered insufficient sample (and hence limited statistical power) to meaningfully test for effect sizes.

${ }^{5}$ Samples are small and thus, for analytical purposes, some regions were grouped together. We start with the Regional Committee (RC) structure implemented within IADI membership and collapse into larger groups which broadly represent continents. This led to the following geographical concordance being constructed, and is used throughout this paper: ASIA: APRC (Asia Pacific RC) + EARC (Eurasia RC); AFRICA: ARC (Africa RC) + MENA (Middle East-North Africa $\mathrm{RC})$; AMERICAS: CRC (Caribbean RC) + LARC (Latin America RC) + RCNA (North America RC); EUROPE: ERC (Europe RC).

${ }^{6}$ It should be acknowledged that independence of the DI legal structure does not necessarily imply operational independence. In many contexts, this distinction in crucial.

${ }^{7}$ There are many potential causal factors for differences in coverage ratios between geographic regions. Detailed exploration of relevant financial data items (such as the variation in saving rates between jurisdictions) are beyond the scope of this paper. Household saving ratios are lower on average in Africa, but these are typically associated with lower levels of deposit insurance coverage, hence not necessarily adversely impacting the coverage ratio.
} 
Fund size in the AMERICAS is larger than in most other regions, and more than $50 \%$ higher than the ASIA and EUROPE figures. There is a reasonable spread across regions regarding this item, but it is difficult to ascertain whether this is significant.

The incidence of pure paybox DI system mandate is much lower in the AMERICAS, and higher in ASIA. This presents possible evidence of a regional effect.

$>$ Privately administered systems tend to be most prevalent in ASIA, double the rates observed in the AMERICAS. However, the potential overall region effect appears relatively small and unlikely to be statistical significant.

\begin{tabular}{|l|l|l|l|l|l|l|}
\hline \multicolumn{6}{|l|}{ TABLE TWO: MEANS BY GEOGRAPHY, 2018} \\
\hline REGION & INDEP & COVER & PAYOUT & FUND & PAYBOX & PRIVATE \\
\hline AFRICA & 0.71 & 16.1 & 33.5 & 2.29 & 0.38 & 0.24 \\
\hline AMERICAS & 0.76 & 57.1 & 34.5 & 2.41 & 0.11 & 0.16 \\
\hline $\begin{array}{l}\text { (Latin } \\
\text { America } \\
\text { only }\end{array}$ & 0.67 & 39.7 & 28.3 & 3.28 & 0.17 & 0.17 \\
\hline $\begin{array}{l}\text { ASIA } \\
\text { EUROPE }\end{array}$ & 0.87 & 43.5 & 25.0 & 1.69 & 0.43 & 0.33 \\
\hline OVERALL & 0.76 & 58.7 & 13.6 & 1.56 & 0.36 & 0.26 \\
\hline
\end{tabular}

\subsection{Summary of variation within regions}

Independence: Findings suggest that the Europe-wide legislative framework has been highly effective at standardising coverage levels, payout efficiency and fund sizes within EUROPE for these EU member states. This is not the same for legal independence - regional variation within EUROPE is far higher than other regions, likely reflecting that the degree of legal independence and other structural factors are not addressed in as much detail in relevant EU legislation'.

\footnotetext{
${ }^{8}$ There is a possibility that substantial heterogeneity may exist within the Americas. The additional line item in the table seeks to shine a light on potential sources of variance between Latin America and the Americas region as a whole. Further exploration of dynamics relating to Latin America follow shortly.

${ }^{9}$ Once again, it should be acknowledged that independence of the DI legal structure does not necessarily imply operational independence. In many contexts, this distinction in crucial.
} 


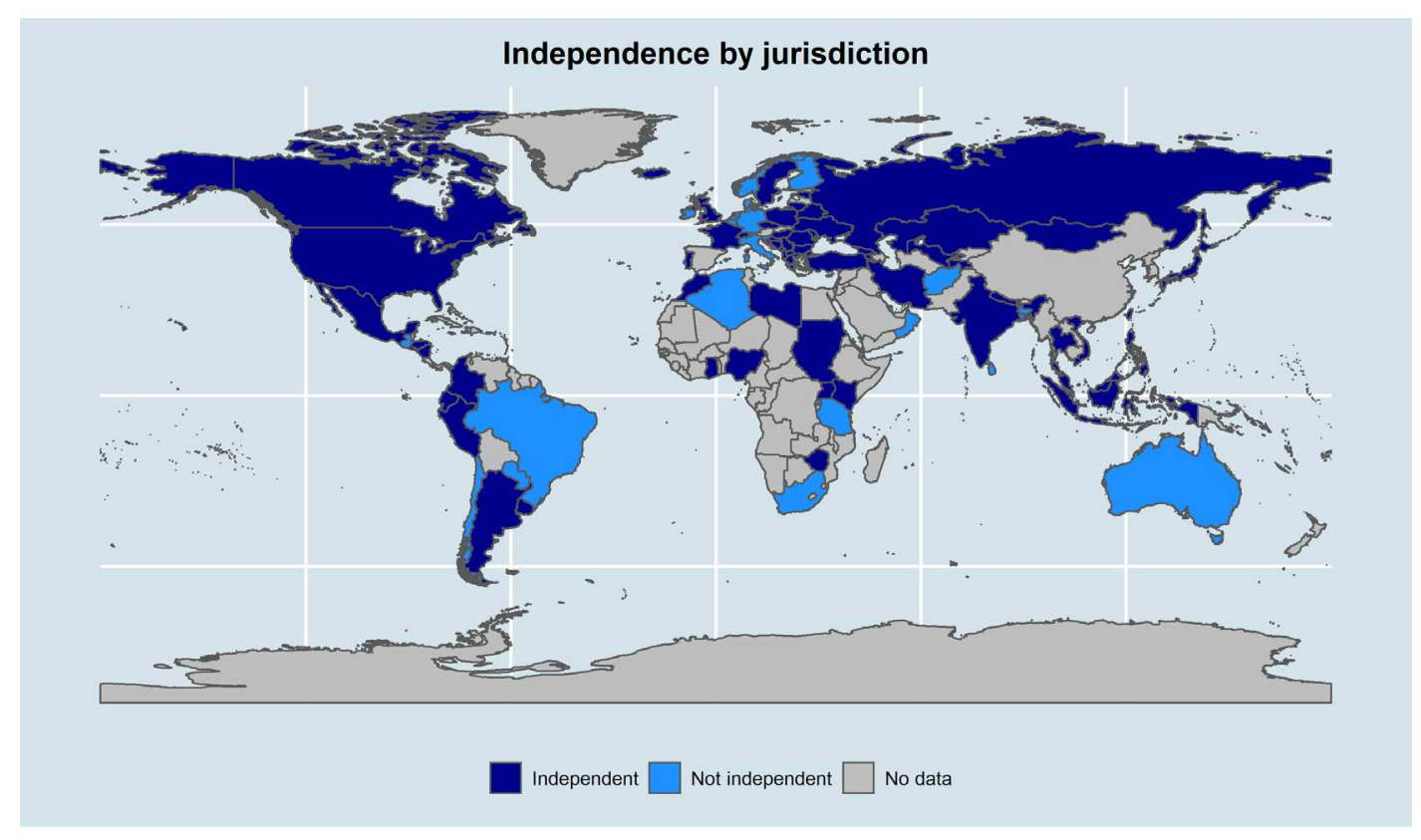

Coverage: Geography is strongly correlated with deposit insurer coverage. The AFRICA region presents the lowest levels of coverage, almost a quarter of those observed in the AMERICAS and EUROPE. ASIA sits somewhat in the middle of other regions for this data item. Coverage ratios are visualised below to represent geographic spread.

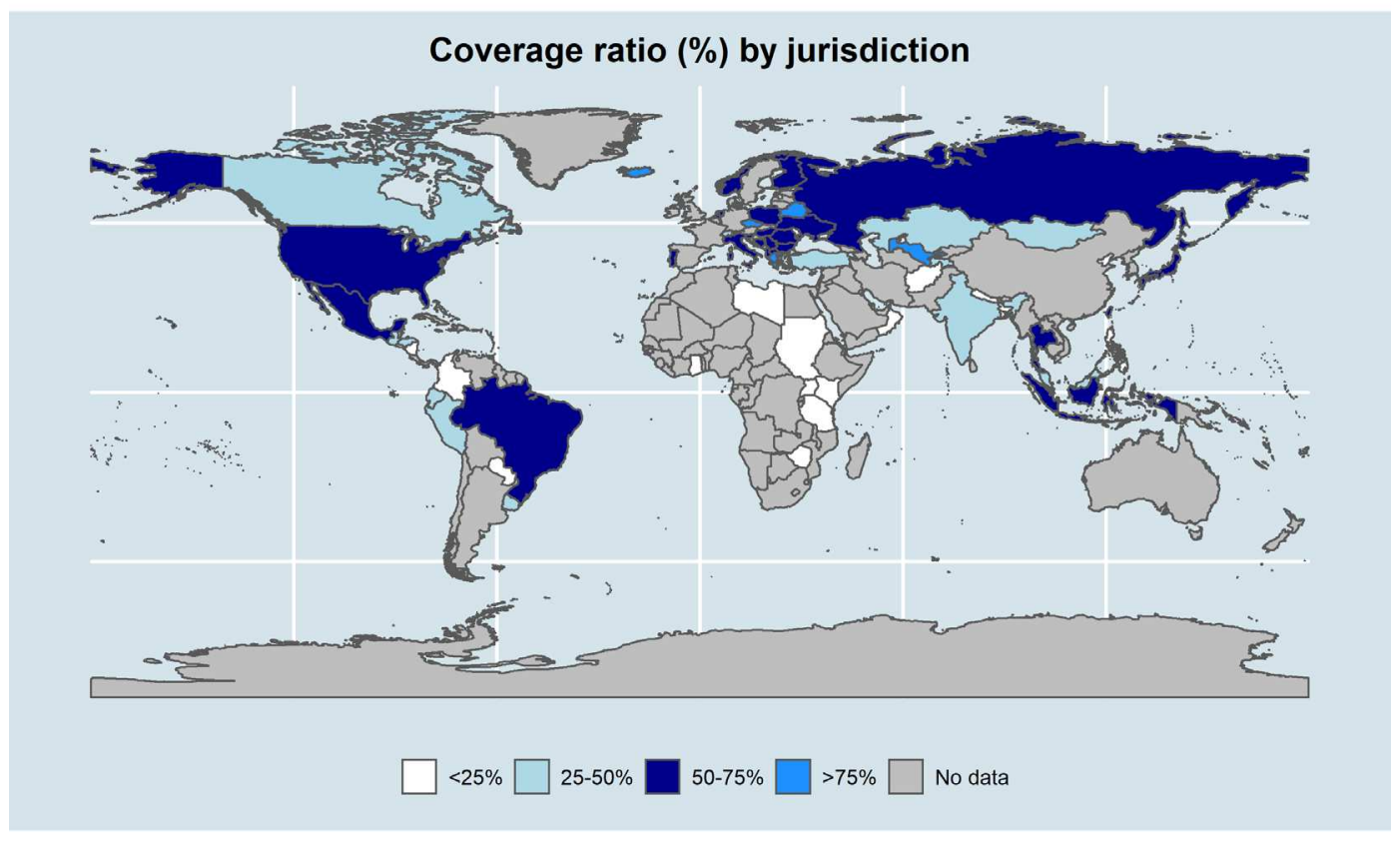

Days to begin payout: This concept differs substantially in terms of the variance within regions. EUROPE is far more homogenous than the AMERICAS. This in part reflects relatively broad adoption of the EU Directive and standards. Increased spread within the AMERICAS is likely to be an artefact driven by the distinction between Caribbean islands and North America, with the latter home to more mature deposit insurance systems. 


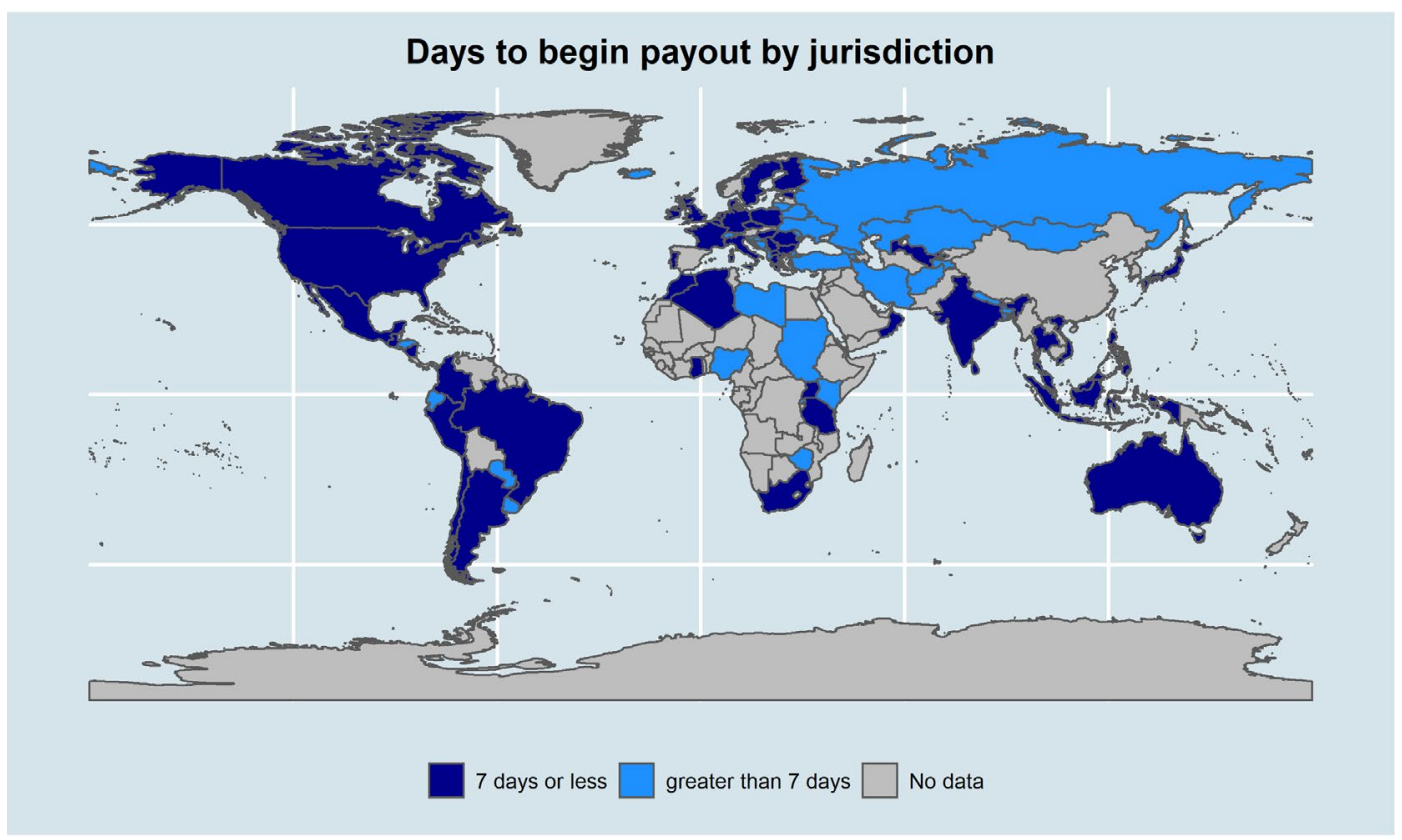

Fund size: AMERICAS region is $30 \%$ greater than the global figure and supports a lack of consistency across the region (mostly driven by Latin America). Greater attention and resourcing could be attributed to coordination and attempts at harmonisation in this region. The opposite is true for AFRICA and EUROPE where fund size variation is low.

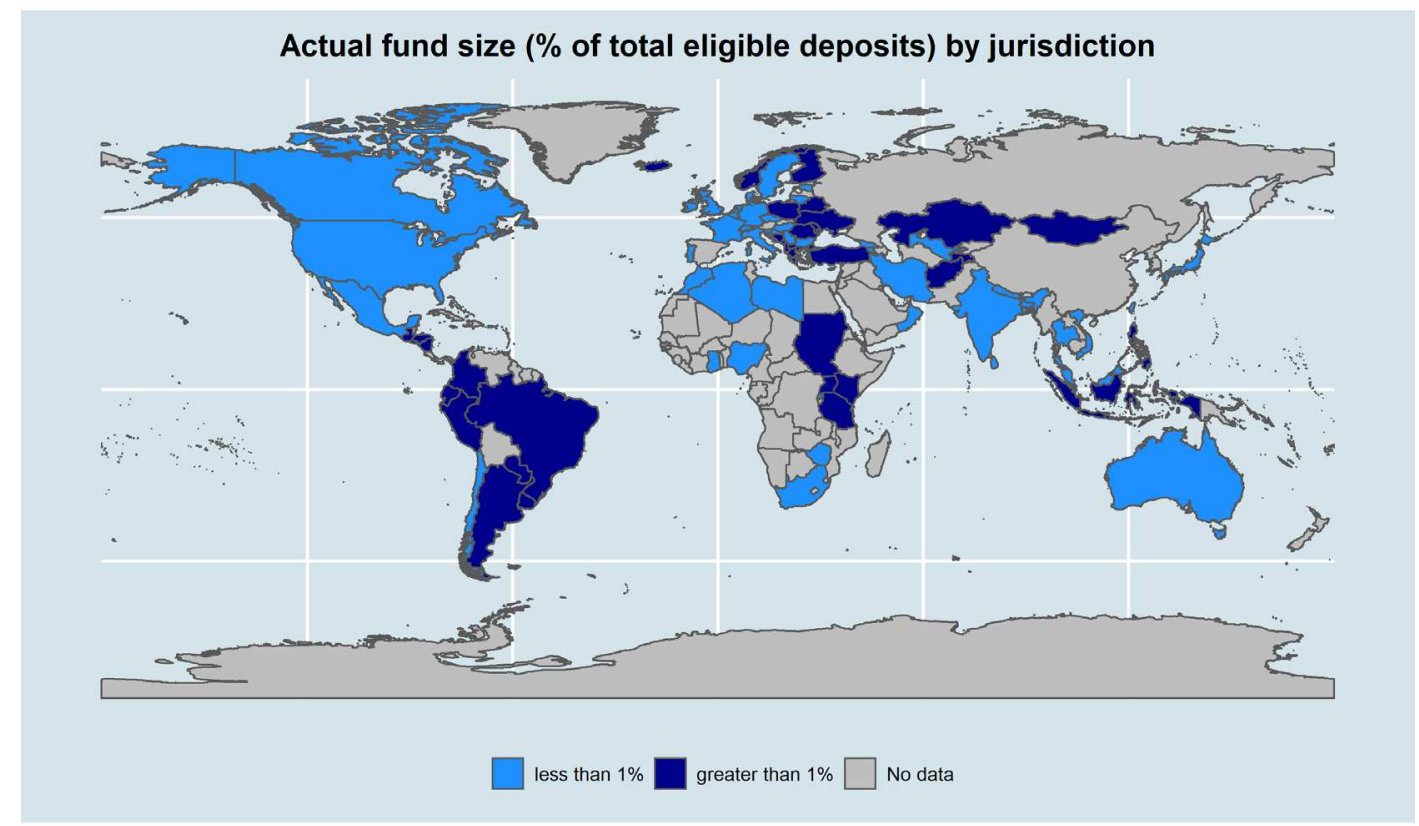

Paybox incidence: Variation within AFRICA, ASIA and EUROPE is quite similar. The AMERICAS have a substantially lower variance within the region. Combined with other summary statistics, it provides evidence that a higher proportion of DI in the region have a mandate broader than a paybox. 


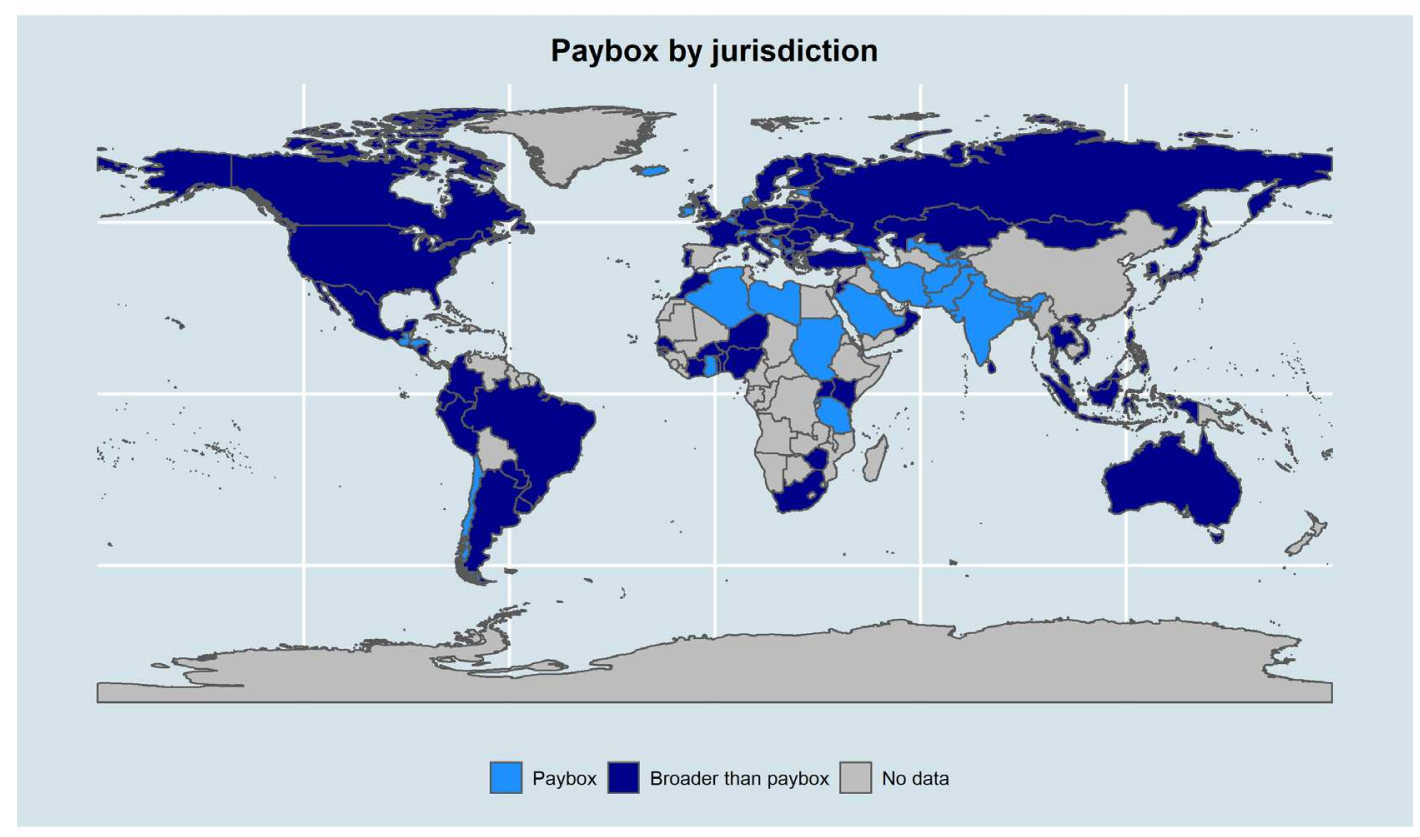

Private administration: There is no clear geographic pattern regarding the prevalence of privately administered deposit insurers. The statistical method is expected to reflect as such.

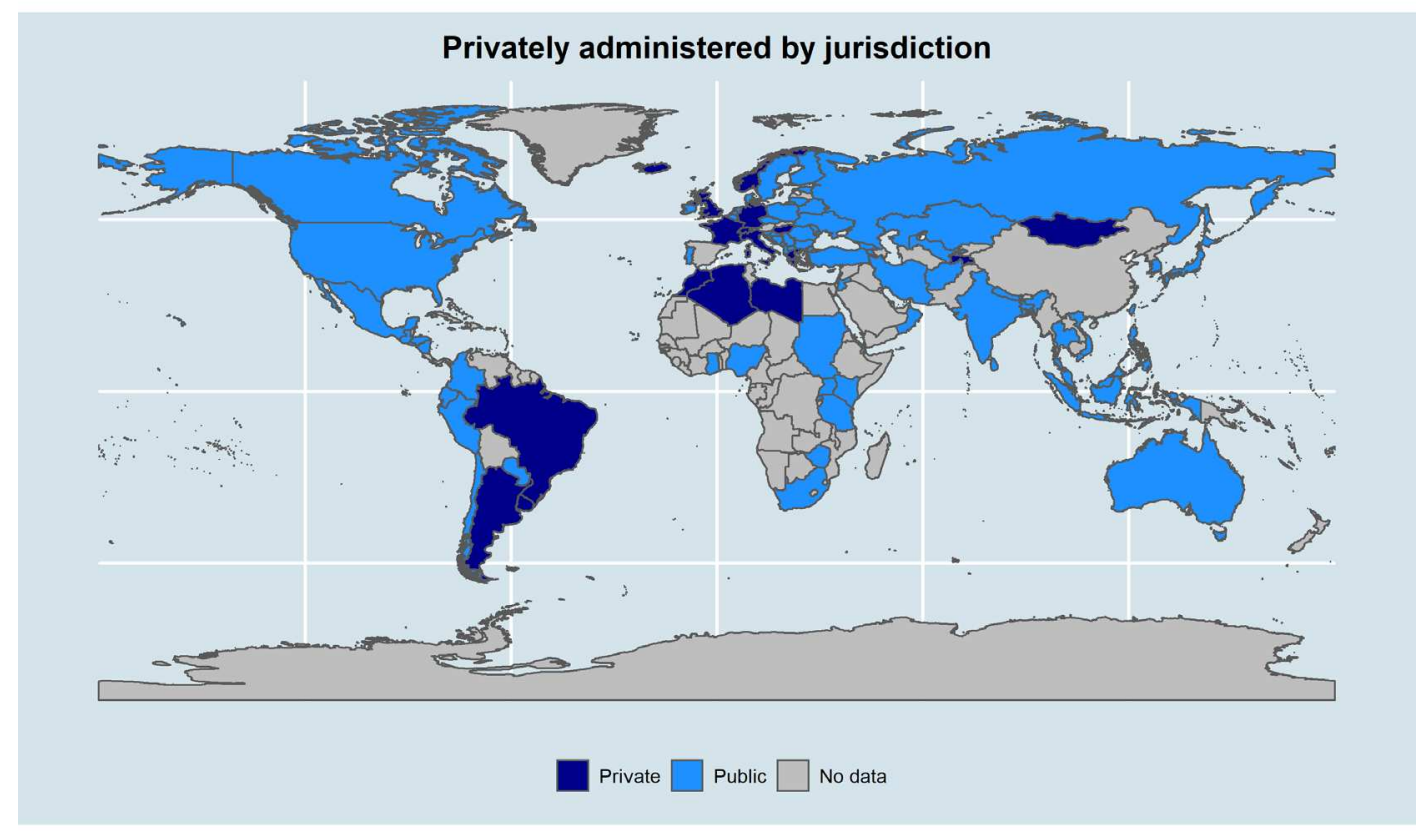

These visual demonstrations combined with simple summary statistics offer some evidence to support the assertion that geography has a role to play in policy deliberations. In the next section, a slightly more formal approach is implemented to account for sample variation, and ultimately determine in the extent to which hypothesised relationships hold true.

\subsection{The model}

The statistical models in this paper seeks to estimate the effect of the regions on each variable of interest, after controlling for $\mathrm{DI}$ age (reasons alluded to earlier in the paper). An interaction effect is also included, which captures the situation where age is only relevant within particular regions, not across the board. In practice, a base region must be selected which facilitates comparison and avoids theoretical assumption violations such as multicollinearity. In this 
case, the base region is chosen to be EUROPE as it has the largest sample and population, hence forming a robust and stable baseline. Therefore, the equation can be rewritten as follows.

$$
\begin{gathered}
\eta_{q, j}=\hat{\alpha}_{0}+\hat{\gamma}_{q} a g e_{j}+\hat{\beta}_{q, 1} R^{(A F R I C A)}+\hat{\beta}_{q, 2} R^{(A M E R I C A S)}+\hat{\beta}_{q, 3} R^{(A S I A)}+\sum_{k=1}^{3} \hat{\delta}_{q, k} a g e_{j} R^{(k)} \\
R^{(k)}=\left\{\begin{array}{lc}
1 ; & \text { if in broad region k } \\
0 ; & \text { otherwise }
\end{array}\right.
\end{gathered}
$$

$k \quad$ index corresponding to AFRICA, AMERICAS and ASIA regions (EUROPE base category omitted)

$j \quad$ index corresponding to all DI in sample

$q \quad$ index corresponding to each data item of interest i.e. INDEP, COVER, PAYOUT, FUND, PAYBOX, PRIVATE

$\eta_{q, j} \quad$ link function for the $\mathrm{j}$-th DI for data item $\mathrm{q}$

$\hat{\beta}_{q, k} \quad$ estimated regional effect for the $k$-th region, for data item $q, k=1,2,3, q=1, \ldots, 6$

$\hat{\gamma}_{q} \quad$ estimated effect for each additional year of $\mathrm{DI}$ age for data item $\mathrm{q}$

$\hat{\delta}_{q, k} \quad$ estimated effect for each additional year of DI age in the $\mathrm{k}$-th region for data item $\mathrm{q}, \mathrm{k}=1,2,3$,

$q=1, \ldots, 6$

The models assume response distribution of Binomial, Normal, Poisson, Normal, Binomial and Binomial respectively for each of the six data items of interest. This leads to the following generalised linear model specifications ${ }^{10}$ :

$y_{q, j} \quad$ value of data item q for the $\mathrm{j}$-th DI

\begin{tabular}{|c|c|c|}
\hline If $y_{q, j}$ is continuous: & If $y_{q, j}$ is binary: & If $y_{q, j}$ is a count: \\
\hline$y_{q, j} \sim \operatorname{Normal}\left(\eta_{q, j}, \sigma^{2}\right)$ & $y_{q, j} \sim \operatorname{Binomial}\left(1, p_{q, j}\right)$ & $y_{q, j} \sim \operatorname{Poisson}\left(\mu_{q, j}\right)$ \\
$\sigma^{2}>0$ & $\log _{e} \frac{p_{q, j}}{1-p_{q, j}}=\eta_{q, j}$ & $\log _{e} \mu_{q, j}=\eta_{q, j}$ \\
& & \\
\hline
\end{tabular}

\section{Results}

Broadly speaking, there was not a statistically significant impact by region in two areas: legal structure and the fund size. There were no regional clusters of DIs with those characteristics. At least one statistically significant regional difference was observed for DI mandate, days to begin payout and coverage ratio. Age of the deposit insurer is a key dynamic for DI mandate and coverage ratio, and is notably above and beyond the effect of region. Days to begin payout experiences a significant interaction effect, whereby age is only driving payout in two regions - faster payouts in the older DI in the AMERICAS and slower payout in older DI in AFRICA.

\subsection{Summary of statistically significant effects}

The table below summarises where effects are present for each respective variable.

\footnotetext{
${ }^{10}$ For generalised linear models, parameters are estimated though maximising the log-likelihood, in this case via weighted least squares.
} 


\begin{tabular}{|c|c|c|c|c|}
\hline \multicolumn{5}{|c|}{$\begin{array}{l}\text { TABLE THREE: SUMMARY OF STATISTICALLY SIGNIFICANT EFFECTS } \\
\text { (5\% SIGNIFICANCE LEVEL) }\end{array}$} \\
\hline VARIABLE & CONCEPT & $\begin{array}{l}\text { REGION } \\
\text { EFFECT }\end{array}$ & $\begin{array}{l}\text { AGE } \\
\text { EFFECT }\end{array}$ & $\begin{array}{l}\text { INTERACTION } \\
\text { EFFECT }^{11}\end{array}$ \\
\hline INDEP & DI legal structure & $x$ & $x$ & $x$ \\
\hline COVER & Coverage ratio (by value) & $\checkmark$ & $\checkmark$ & $x$ \\
\hline PAYOUT & $\begin{array}{l}\text { What is the targeted number of days to begin deposit } \\
\text { reimbursement? }\end{array}$ & $\checkmark$ & $x$ & $\checkmark$ \\
\hline FUND & Actual fund size (as a percentage of total eligible deposits) & $x$ & $x$ & $x$ \\
\hline PAYBOX & Is the $\mathrm{DI}$ a paybox? & $\checkmark$ & $\checkmark$ & $x$ \\
\hline PRIVATE & Is the DI privately administered? & $x$ & $x$ & $x$ \\
\hline
\end{tabular}

The aforementioned analysis has presented the extent to which results can differ between regions. This only paints part of the picture. One dynamic of interest is the degree to which responses differ within a region. To capture this we calculate a rather simple measure of spread, the standard deviation. High values imply more spread and hence greater heterogeneity within a region, while smaller values suggest homogeneity.

\begin{tabular}{|c|c|c|c|c|c|c|c|c|c|c|c|c|}
\hline \multicolumn{13}{|c|}{ TABLE FOUR: STANDARD DEVIATION WITHIN REGION ${ }^{12}$} \\
\hline \multirow[t]{2}{*}{ REGION } & \multicolumn{2}{|l|}{ INDEP } & \multicolumn{2}{|l|}{ COVER } & \multicolumn{2}{|l|}{ PAYOUT } & \multicolumn{2}{|l|}{ FUND } & \multicolumn{2}{|l|}{ PAYBOX } & \multicolumn{2}{|l|}{ PRIVATE } \\
\hline & \begin{tabular}{|l} 
Regional \\
variatio \\
$n$
\end{tabular} & $\begin{array}{l}\text { Deviatio } \\
\text { n } \quad \text { from } \\
\text { overall }\end{array}$ & \begin{tabular}{|l} 
Regional \\
variatio \\
$n$
\end{tabular} & $\begin{array}{l}\text { Deviatio } \\
\text { n from } \\
\text { overall }\end{array}$ & $\begin{array}{l}\text { Regional } \\
\text { variatio } \\
n\end{array}$ & $\begin{array}{l}\text { Deviatio } \\
n \quad \text { from } \\
\text { overall }\end{array}$ & \begin{tabular}{|l} 
Regional \\
variatio \\
$n$
\end{tabular} & $\begin{array}{l}\text { Deviatio } \\
\text { n from } \\
\text { overall }\end{array}$ & $\begin{array}{l}\text { Regional } \\
\text { variatio } \\
n\end{array}$ & $\begin{array}{l}\text { Deviatio } \\
\text { n } \quad \text { from } \\
\text { overall }\end{array}$ & $\begin{array}{l}\text { Regional } \\
\text { variatio } \\
n\end{array}$ & $\mid \begin{array}{ll}\text { Deviatio } \\
n & \text { from } \\
\text { overall }\end{array}$ \\
\hline AFRICA & 0.46 & $7 \%$ & 13.3 & $-52 \%$ & 25.2 & $-27 \%$ & 1.72 & $-26 \%$ & 0.50 & $9 \%$ & 0.44 & $2 \%$ \\
\hline $\begin{array}{l}\text { AMERICA } \\
S\end{array}$ & 0.43 & $0 \%$ & 28.2 & $1 \%$ & 53.4 & $54 \%$ & 2.97 & $28 \%$ & 0.31 & $-33 \%$ & 0.37 & $-14 \%$ \\
\hline ASIA & 0.35 & $-19 \%$ & 27.6 & $-1 \%$ & 33.2 & $-5 \%$ & 2.09 & $-10 \%$ & 0.50 & $9 \%$ & 0.48 & $12 \%$ \\
\hline EUROPE & 0.46 & $7 \%$ & 21.9 & $-21 \%$ & 17.6 & $-49 \%$ & 1.67 & $-28 \%$ & 0.49 & $7 \%$ & 0.44 & $2 \%$ \\
\hline \begin{tabular}{|l|} 
OVERALL \\
\end{tabular} & & .43 & & 7.8 & & 4.8 & & .32 & & .46 & & .43 \\
\hline
\end{tabular}

Fund size sees the AMERICAS region stand out as a noteworthy case. Its variation is $30 \%$ greater than the global figure and supports a lack of consistency in fund size within this very broad and diverse region. This is not unexpected as we generally observe higher payout efficiency in North America compared to Latin America. The opposite is true for AFRICA and EUROPE where fund size variation is low. It is intuitive to attribute the relative homogeneity in Europe to the diligent adoption of EU legislation. The driver behind similar consistency in AFRICA remains undetermined.

\footnotetext{
${ }^{11}$ Age by region interaction.

12 Percentages indicate relative deviation of region-specific measure from overall variable measure

e.g. for AFRICA/INDEP: $(0.46-0.43) / 0.43 * 100=7 \%$
}

IADI Policy Brief No. 2 
A further statistical check utilising a chi-squared testing framework presents sufficient evidence that the regional variation for both the coverage ratio and days to payout is significantly different from the overall variation. The Appendix provides further detail on this approach.

\subsection{Technical assistance considerations}

Determining the options in which IADI technical assistance resources could be distributed among the considerable needs of stakeholders is a complicated trade-off for decision-makers. Some factors to consider might include:

a. Magnitude of gap(s) must be sufficient to warrant remediation. The extent of perceived gaps in Core Principle alignment, as judged by data or via expert opinion, can help in calibrating training and technical assistance initiatives.

b. Capacity to change considerations and experience highlight that many characteristics within a given system are not able to be adjusted easily upon receipt of advice or recommendation. For instance, major funding changes are typically slow moving due to the need for extensive consultation among stakeholders as well as potential fiscal/budget constraints.

c. Geographic homogeneity in gap identification within a given region can enable cost-effective training to be highly targeted and with high efficacy in meeting a broad range of stakeholder needs. Regions with greater heterogeneity in capability gaps can be difficult to address through traditional approaches such as conferences and workshops.

d. Common institutional structures can yield common challenges. Organisations with similar operational structure, legislative environments, policy settings, and governance frameworks will likely face common challenges regardless of region. Therefore, targeting training at a group of organisations that are not dissimilar can reap benefits.

e. Supply of experts will limit the capacity to offer training in some regions. Technical assistance relies on an available supply of suitable trained experts who can offer their insights and judgement. Many highly specialised areas can face challenges in sourcing appropriate talent.

f. Training funding is required to run any training of technical assistance program. It is often the case that those requiring the most assistance will have fewest funds to engage technical experts, and will therefore require help from IADI and other international organisations.

\subsection{Technical assistance implications}

The statistically significant region effect observed for the coverage ratio and days to payout suggest that there may be benefits in tailoring training and technical assistance to these themes, with a particular focus on AFRICA. The AMERICAS show considerable within-region variation for days to payout, with Latin American nations exhibiting different outcomes to the rest of the AMERICAS.

Further investigation may be needed to explore the reasons why (on average) older institutions in AFRICA appear to take longer, on average, to payout than younger institutions. Perhaps this reflects that newer systems may be introducing more state-of-the-art payout IT systems, while more established systems may rely on legacy information systems. Or there may be a structural issue within the region preventing improvements in payout outcomes. Provided no fundamental road blocks are found, more training and technical assistance may be a feasible option to improve alignment with the IADI Core Principles on this matter.

Coverage ratios provide the largest amount of variation within and between regions, even after using relative measures. Levels of coverage differ the least within AFRICA and EUROPE, and the most in the AMERICAS and ASIA (perhaps reflecting greater intra-regional variation in incomes and average deposit levels). The model estimates support the assessment that coverage levels in AFRICA and EUROPE are systematically (and consistently) low and high respectively, on a global scale. Relevant training and technical assistance initiatives might therefore take this result into account when allocating resources. 
The results are interesting when compared against alternative analyses of IADI member training and technical assistance needs. López (2016) found that the regions did not consist of enough common requirements to warrant targeting of technical assistance in any given geographic area. Conversely, this paper shows that for some deposit insurer characteristics, the source of variation is between regions rather than within. This suggests that for very specific data item and region combinations, technical assistance could indeed be targeted at a regional level.

\subsection{The European effect}

European respondents made up 35\% of the 2018/19 IADI Annual Survey dataset ${ }^{13}$. As such, they carry a large weight when attempting to draw conclusions about the membership as a whole, particularly given the strong degree of homogeneity in their structure, operations and policy objectives arising from membership or affiliation with the EU. By excluding EUROPE from the analysis, we can ascertain the extent to which this block may be distorting model results. This also explores a probable future state of affairs as deliberations concerning an EU-wide deposit insurer are well advanced. We omit EUROPE from the model and change reference category to the AMERICAS, which then made up the largest proportion of responses remaining.

A notable observation is that the age effect observed with coverage ratio washes out when EUROPE is omitted. This is an intuitive result as EUROPE does on average have one of the higher coverage ratios by region and contains a disproportionately high number of more mature systems. Results relating to the paybox data item evolve in a similar way, with the age effect disappearing after European deposit insurers are set aside from the model. To summarise, the omission of EUROPE from the analysis changed the way DI age is interpreted across a subset of data items. Such a result, along with high levels of homogeneity within the region, may offer some evidence supporting separate treatment of EUROPE in future analyses of this kind.

\subsection{Disaggregating the Americas}

Earlier in the paper, it was asserted that effects attributed to the AMERICAS might be influenced by heterogeneity within the region. This is hypothesised to manifest mainly through differences between Latin America and North America. The assertion was tested formally through splitting out Latin American deposit insurers from the AMERICAS and the model re-run (disaggregated region, age and interaction components all included). Days to payout was the only data item where a statistically significant effect was identified. Latin America was approximately $35 \%$ faster at paying out than the rest of the AMERICAS region. Older DI in Latin America were also likely to have faster payouts approximately one day faster for every additional ten years of age.

\section{Future directions}

This paper merely scratches the surface in exploring the implications of geography on deposit insurance design features and characteristics. Further research is encouraged to draw additional insights and see if there is a way to convert findings into practical initiatives for the benefit of IADI members and future research as a whole. Possible future work might include any of the following:

a. Extending the analysis to a wider suite of survey variables. Six were selected in part to keep the paper manageable, but there is no reason why the simple methodology in this paper could not be expanded upon.

b. Design and distribute a follow-up survey to members seeking to further target the dynamics driving both inter- and intra-regional variation e.g. looking at how deposit insurers perceive the policy settings of other jurisdictions in their region. Sample composition could range from population-representative sampling to targeting of a given region of interest, or a succinct number of key jurisdictions that would underpin useful case studies.

c. Consider a temporal dimension i.e. time series and cross-sectional approach, and whether there is evidence to suggest an evolution of relationships between key data items over time. Of particular interest would be comparing observations before and after times of 2008 global financial crisis. IADI maintains a DI-level panel

\footnotetext{
${ }^{13}$ Europe constitutes 47 (35\%) of the 135 responses. Africa, the Americas, and Asia contribute 21 (16\%), 37 (27\%), and 30 (22\%) respectively.
}

IADI Policy Brief No. 2 
dataset that would be suitable for such an analysis. It would provide sufficient granularity to enable fixed effects models to be estimated and appraised, or alternatively a more flexible framework such as structural equation modelling.

d. Consider more carefully possible geographic causational links when examining trends in deposit insurance and future research and guidance for the Association.

\section{References}

International Association of Deposit Insurers. (2014). Revised Core Principles for Effective Deposit Insurance Systems. IADI Guidance Paper.

International Association of Deposit Insurers. (2019). IADI Annual Survey. IADI Data Files.

López, J. (2016). Technical Assistance: A Different Approach. IADI Conference Presentation. 


\section{Appendix}

\subsection{Model parameter estimates}

\begin{tabular}{|c|c|c|c|c|c|c|}
\hline EFFECT & INDEP & COVER & PAYOUT & FUND & PAYBOX & PRIVATE \\
\hline Age $(\hat{\gamma})$ & -0.05 & 0.74 & 0.01 & 0.03 & $-0.11^{*}$ & -0.01 \\
\hline AFRICA $\left(\widehat{\beta_{1}}\right)$ & -0.27 & $-12.61^{* *}$ & $0.69 * * *$ & 2.37 & -1.29 & -0.65 \\
\hline $\begin{array}{l}\text { AMERICAS } \\
\left(\widehat{\beta_{2}}\right)\end{array}$ & -0.97 & -15.67 & $2.15^{* * *}$ & 1.66 & $-1.53^{*}$ & -1.08 \\
\hline $\mathrm{ASIA}\left(\widehat{\beta_{3}}\right)$ & -0.27 & $1.31^{*}$ & $0.38^{* *}$ & 1.60 & -1.49 & 1.04 \\
\hline $\begin{array}{l}\text { AFRICA-Age } \\
\text { interaction } \\
\left(\hat{\delta}_{1}\right)\end{array}$ & 0.06 & -1.55 & $0.19 *$ & -0.09 & 0.06 & 0.04 \\
\hline $\begin{array}{l}\text { AMERICAS- } \\
\text { Age } \\
\text { interaction } \\
\left(\hat{\delta}_{2}\right)\end{array}$ & 0.05 & 0.15 & $-0.06 * * *$ & -0.04 & -0.01 & 0.02 \\
\hline $\begin{array}{l}\text { ASIA-Age } \\
\text { interaction } \\
\left(\hat{\delta}_{3}\right)\end{array}$ & 0.05 & -0.91 & 0.01 & -0.07 & 0.10 & -0.04 \\
\hline
\end{tabular}

\subsection{Chi-squared test of regional variation}

In order to introduce additional statistical rigour to the analysis of within-region variation, we consider a chi-squared test. This test uses the chi-square distribution, to test whether there is a significant difference between observed frequencies and expected frequencies for a data set. The relevant test statistic is defined as follows:

$$
\chi_{T E S T, q}^{2}=\sum_{k=1}^{4} \frac{\left(R V_{q, k}-V_{q}\right)^{2}}{V_{q}}
$$

$R V_{q, k} \quad$ variation within region $\mathrm{k}$ for data item $\mathrm{q}$

$V_{q} \quad$ variation over all regions for data item $q$ (row listed as 'OVERALL' in TABLE FOUR)

$k \quad$ index corresponding to the four regions AFRICA, AMERICAS, ASIA and EUROPE

For each data item q, we construct a hypothesis test. The null hypothesis $\left(H_{0}\right)$ corresponds to all regions presenting the same level of variation, while the alternative $\left(H_{A}\right)$ is naturally defined as the complement. Evidence is gathered against $H_{0}$, with sufficient evidence needed to warrant its rejection, subject to some pre-specified level of Type I error.

$H_{0}: R V_{q, 1}=R V_{q, 2}=R V_{q, 3}=R V_{q, 4}=V_{q} ; H_{A}:$ not $H_{0}$

$14 *, * *, * * *$ denote statistical significance of model coefficients at $5 \%, 1 \%$ and $<1 \%$ level respectively 
Under $H_{0}, \chi_{T E S T, q}^{2}$ is distributed as a $\chi^{2}$ distribution with 3 degrees of freedom, for each data item q. A p-value can then be determined to assess the likelihood of such a sample outcome occurring under the null hypothesis (and given Type I error of $\alpha=5 \%$ ).

p-value $\mathrm{q}_{\mathrm{q}}=\operatorname{Pr}\left(\chi_{T E S T, q}^{2}>\chi_{\alpha, 3}^{2}=7.82\right)$

\section{TABLE SIX: CHI-SQUARED TEST OF VARIATION WITHIN REGIONS}

\section{(5\% SIGNIFICANCE LEVEL)}

\begin{tabular}{|l|l|l|l|l|l|l|}
\hline EFFECT & INDEP & COVER & PAYOUT & FUND & PAYBOX & PRIVATE \\
\hline Test statistic & 0.019 & 8.822 & 21.164 & 0.542 & 0.058 & 0.015 \\
\hline p-value & $99.9 \%$ & $3.2 \%$ & $0.0 \%$ & $91.0 \%$ & $99.6 \%$ & $100.0 \%$ \\
\hline Significant? & $\mathbf{X}$ & $\checkmark$ & $\checkmark$ & $\mathbf{X}$ & $\mathbf{X}$ & $\mathbf{X}$ \\
\hline
\end{tabular}

Results in the table above support the assessment that coverage ratios and days to payout differ between regions in terms of intra-region variation ${ }^{15}$.

\subsection{Testing for interventions post-2008/09}

The model discussed in this paper assumes that any age effects develops in a linear matter over time i.e. searching for evidence of gradual change rather than reform during any short time interval. An alternative parameterisation enables one to test for changes before and after 2008/09, corresponding to the considerable reform period that emerged as a result of the 2008/09 Global Financial Crisis ${ }^{16}$.

Using the same notation as discussed earlier, the continuous age variable is replaced with a dummy. This dummy takes a value of one for those deposit insurers created in 2009 or later, and zero otherwise. Changes from the original model are highlighted in bold.

$$
\begin{aligned}
& \operatorname{age2009}_{j}=\left\{\begin{array}{l}
1 \\
\text { if DI created in } 2009 \text { or later } \\
0 \quad \text { if DI created before } 2009
\end{array}\right. \\
& \eta_{q, j}=\hat{\alpha}_{0}+\hat{\gamma}_{q} \boldsymbol{a g e \mathbf { 2 0 0 9 } _ { j }}+\hat{\beta}_{q, 1} R^{(A F R I C A)}+\hat{\beta}_{q, 2} R^{(A M E R I C A S)}+\hat{\beta}_{q, 3} R^{(A S I A)}+\sum_{k=1}^{3} \hat{\delta}_{q, k} \boldsymbol{a g e 2 0 0 \mathbf { g } _ { j } R ^ { ( k ) }}
\end{aligned}
$$

Statistical significance of the marginal age effect changes for two data items, namely the coverage ratio (COVER) and days to begin payout (PAYOUT). For COVER, we discover that the age effect is likely to be more gradual over a long period of time. Conversely, for PAYOUT we observe that the 2008/09 saw a relatively sudden reduction in the number of days to commence a payout.

It should also be noted that the PAYBOX data item maintains a significant age effect in both models. This infers that while a general broadening out of the deposit insurer role in resolution has been occurring over time, the 2008/09 period can also be considered a major period of reform (above and beyond the longer term trend).

\footnotetext{
${ }^{15}$ Results do not differ when the chi-squared test is applied to sample frequencies.

${ }^{16}$ This period also broadly corresponds to when the IADI Core Principles were first issued, thus formalising the standards by which deposit insurers should operate.
} 


\begin{tabular}{|c|c|c|c|c|}
\hline \multicolumn{5}{|c|}{$\begin{array}{l}\text { TABLE SEVEN: SUMMARY OF STATISTICALLY SIGNIFICANT EFFECTS } \\
\text { (5\% SIGNIFICANCE LEVEL) }\end{array}$} \\
\hline VARIABLE & CONCEPT & $\begin{array}{l}\text { REGION } \\
\text { EFFECT }\end{array}$ & $\begin{array}{l}\text { AGE } \\
\text { EFFECT }\end{array}$ & $\begin{array}{l}\text { INTERACTION } \\
\text { EFFECT }{ }^{17}\end{array}$ \\
\hline INDEP & DI legal structure & $x$ & $x$ & $x$ \\
\hline COVER & Coverage ratio (by value) & $\sqrt{ }$ & $x$ & $x$ \\
\hline PAYOUT & $\begin{array}{l}\text { What is the targeted number of days to begin deposit } \\
\text { reimbursement? }\end{array}$ & $\checkmark$ & $\checkmark$ & $\checkmark$ \\
\hline FUND & Actual fund size (as a percentage of total eligible deposits) & $x$ & $x$ & $x$ \\
\hline PAYBOX & Is the DI a paybox? & $\checkmark$ & $\checkmark$ & $x$ \\
\hline PRIVATE & Is the DI privately administered? & $x$ & $x$ & $x$ \\
\hline
\end{tabular}

\footnotetext{
${ }^{17}$ Age by region interaction.
}

IADI Policy Brief No. 2 